Journal of Social Sciences 8 (2): 216-222, 2012

ISSN 1549-3652

(C) 2012 Science Publications

\title{
Approaches to Learning in First Year University Physics
}

\author{
${ }^{1}$ Rachel Wilson, ${ }^{1}$ Steve Georgakis and ${ }^{2}$ Manjula Sharma \\ ${ }^{1}$ Faculty of Education and Social Work, University of Sydney, Sydney, Australia \\ ${ }^{2}$ School of Physics, University of Sydney, Australia
}

\begin{abstract}
Problem statement: In recent decades, discipline specific ways of thinking and knowing have gained increased recognition in understanding learning. However, there has been little empirical research examining student approaches to learning within specific disciplines or, even more specifically, within different streams of study or in response to different curriculum within a discipline. Approach: The aim of this study was to investigate student approaches to learning in physics. We explore whether different streams of study or exposure to different syllabi are associated with deep or surface approaches to learning. A total of 2,030 first year physics students at an Australian metropolitan university over three different year cohorts and three streams completed an adaptation of the Study Processes Questionnaire (SPQ) which produces measures of Deep and Surface approaches to learning. Students studied within 'Advanced', 'Regular' and 'Fundamentals' streams, based upon prior experience in physics study. Students within the three cohorts were exposed to different senior high school syllabi, as the exam board introduced a new and innovative syllabus. We make comparison on approaches to learning across streams and across the three year cohorts. Results: Findings show that the behavior of the mean scale scores for students in different streams in first year physics is in agreement with expectations; advanced streams reported higher levels of deep approaches while Fundamentals streams reported higher levels of surface approaches. Furthermore, different year cohort performance on the scales reflects changes in senior high school syllabus; with a new syllabus reflecting a shift toward more deep approaches to learning. Conclusion/Recommendations: It is promising to see that revision of syllabi has a direct impact upon student approaches learning. A challenge lies in ways to best harness this power and to address the trends seen in student approaches to learning across streams.
\end{abstract}

Key words: Study Processes Questionnaire (SPQ), Study Behaviour Questionnaire (SBQ), learning contexts, tangible frameworks, Learning Processes Questionnaire (LPQ)

\section{INTRODUCTION}

Informed student-centred teaching and learning practices require teachers to reflect on the experiences, study habits and orientation to learning of their students. Since the mid 1960's a series of inventories exploring student learning in higher education have been developed based on learning theories, educational psychology and study strategies. For reviews of the six major inventories see Entwistle and McCune (2004) and Biggs (1993). Even though the inventories differ in their theoretical basis and embedded constructs, they have two common components: a study habits and strategies component and a cognitive processes component. Studies comparing the inventories have found reasonable conceptual overlap amongst the inventories often with some re-sorting of items (see for example Christensen et al., 1991; Wilson et al., 1996).

The rationale for the use of such inventories in higher education is built upon two premises: first, inventories enable students to report their study intentions, habits and the cognitive processes involved in a coherent manner. Second, the university environment is such that it provides flexibility for students to adapt their ideas of knowledge and study methods to different learning contexts. By better understanding student approaches to learning within different learning contexts research using inventories can serve to promote higher quality teaching (Laird and Garver, 2010). This study is interested in exploring student approaches to learning within physics, in the hope that a more detailed knowledge of approaches within different streams and in response to different curricula will inform faculty teaching and learning practice.

The popularity of the inventories resides in the fact that they can be related to tangible frameworks for promoting teaching and learning in higher education. The Study Processes Questionnaire (SPQ) has been chosen for this study, as it is integrated with the well-developed presage-process-product model (3P model) of teaching and learning (Biggs, 1987a). In addition, the SPQ has

Corresponding Author: Rachel Wilson, Faculty of Education and Social Work, University of Sydney, Sydney, Australia 


\section{J. Social Sci., 8 (2): 216-222, 2012}

been used across cultures and years (see, for example, Gow et al., 1994; Zeegers, 2001; Burnett and Dart, 2000; Kember et al., 2008) and either for, or with the intent of, comparing student approaches in different disciplines, such as accounting, psychology and biology with considerable success (Skogsberg and Clump, 2003; Quinnell et al., 2005).

The SPQ, developed by Biggs (1987a; 1987b) draws on the information processing model of Craik and Lockhart (1972). Their 'levels of processing' model proposed that the depth of active processing in the original learning would determine the nature and extent of subsequent memory of the episode. Craik (1979) identified two central postulates in their model. Firstly, that deep cognitive coding relies upon semantic analysis that is more meaningful and therefore more durable than surface codes which are non-semantic and rely upon superficial processing. Secondly, that processing of codes, or learning, is not limited by capacity but is primarily determined by the depth of processing applied. By placing this understanding within a framework that recognised that individual learners react in a way that is typical for them, as well as in a way determined by a particular context (Biggs 1987a), theorised that processing strategies, both deep and surface, might be identified and studied within different educational contexts. The precursor to the SPQ was the Study Behaviour Questionnaire (SBQ)-an 80 item questionnaire with ten scales: pragmatism, academic motivation, academic neuroticism, internality, study skills, rote learning, meaningful learning, test anxiety, openness and class dependence. The SPQ was developed in parallel with the Learning Processes Questionnaire (LPQ) for high school students.

The question of whether one version of the SPQ can be used across different disciplines as opposed to a proliferation of inventories for different disciplines raises several issues. First, if the research questions relate to general features of the teaching and learning context within the framework of the $3 \mathrm{P}$ model, then the SPQ as it stands is adequate for all discipline areas. However, if the research questions require resolution of detail specific to the discipline then a discipline specific version is necessary. Second, if the study design aims to minimize systematic error and bias likely introduced by students experiencing different disciplines within the local context, then a discipline specific version maybe necessary. Third, as a community we acknowledge that the ways of thinking learning and knowing may be different across discipline areas by the emergence of theories such as the Model of Domain Learning (Alexander et al., 1997; Langan and Athanasou, 2005) and studies demonstrating the need for understanding subject-related trends (Jacobs and Newstead, 2000; Laird and Garver, 2010). Laird and collegues clearly demonstrated disciplinary differences in the prevalence of deep approaches to learning (Laird et al., 2008). With these issues in mind it was decided to use the SPQ with minimal adaptation by the insertion of the word 'physics' into most items. This was done so that student response would not be oriented to their overall approach to learning but would focus specifically upon their learning in physics. By modifying the SPQ further insight into learning in physics can be gained.

Such modification is not unusual in the use of these inventories. Research using modified SPQ versions has uncovered new issues, but the theoretical frameworks and conceptual bases stand the test of time. For example Kember et al. (1999) argue the case for two versions of the SPQ, one for teaching evaluation and development, another for sophisticated research applications. An 18-item version of the SPQ, demonstrated the same factor structure as the 42-item version in a study with medical students (Fox et al., 2001). Crawford et al. (1998a; 1998b) adapted the SPQ into the Approaches to Learning Mathematics Questionnaire when trying to obtain discipline specific understandings of student conceptions of mathematics.

The SPQ has been used to compare student approaches in different disciplines, such as accounting, psychology and biology with considerable success (Skogsberg and Clump, 2003; Quinnell et al., 2005). To date, our literature searches have found, no study examining the diversity of approaches that may occur within a disciplinary degree in naturally occurring subgroups, like course streams. Nor has the impact of curricular reform been examined in regard to students reported approaches to learning. What has been explored extensively is how student approaches change with innovations in teaching and learning (Kember et al., 2008). This study aims to address these gaps by focusing on three aspects of students' approaches to learning: how they might be assessed and relevant to physics, how they might relate to prior experience and attainment in the subject (as reflected in different streams of first year student) and how they might shift with syllabus and curricular reform.

\section{MATERIALS AND METHODS}

The methodology of this study is designed to answer three research questions:

- What are the reported approaches to learning of students in first year physics?

- Is there any association between reported deep and surface approaches to learning and different streams of first year physics? 


\section{J. Social Sci., 8 (2): 216-222, 2012}

- Is there any association between reported deep and surface approaches to learning and exposure to different high school physics curriculum?

Participants: The context for this study is the School of Physics at a research focused, urban Australian university. The School offers three mainstream physics units of study to students in their first semester of university. The Fundamentals unit is primarily for students who have done no physics in senior high school, although it also caters for those who have done poorly in senior high school physics. The Regular unit is for students who have attained well in senior high school physics, while the advanced unit is for those who have done senior high school physics and are exceptionally high attainers. The three units effectively group students according to their backgrounds in senior high school physics. The teaching methods and environment at university are the same across the three units but the depth of content varies.

The students in the three units can be enrolled in a wide range of degree programs such as Engineering, Medical Science and Arts. Physics majors and indeed postgraduate students are drawn from these three units. However, the largest fractions continuing with physics are from the advanced stream, followed by Regular and lastly Fundamentals. A comparison of student demographics across the three streams shows that 63 percent of the Fundamentals stream is female in comparison to approximately 30 percent females in the other streams. However, the three streams are comparable in most aspects.

The participants of this study also come from first year intake cohorts in 2000, 2001 and 2004, with a total of 2,030 students. Over this four year period there were dramatic changes to the state high school physics syllabi and assessment systems NSW, Board of Studies, 2011, which was reflected in changing pedagogy and learning in high school classroom. Consequently the 2004 cohort were exposed to a different high school physics curriculum. Details of the change in syllabi are reviewed in Binnie (2004). This study will examine whether this shift has had any discernable impact upon student approaches to learning. In a related qualitative study, using phenomenography it was shown that student' conceptions of physics as a subject shifted with the introduction of a revised physics syllabus (Wilson et al., 2011).

Procedure: The physics SPQ was administered to students during the first laboratory session of first semester in the three streams in 2001, 2002 and 2004, with informed participant consent. The response rate was $95 \%$ for $2001,65 \%$ for 2002 and $85 \%$ for 2004 .
The lower response rate in 2002 is due to changes in class organisation and the methods employed for questionnaire administration. The questionnaire was administered by at least thirty different academic and casual staff during laboratory sessions with other intensive activities occurring immediately before and after the questionnaires. Standard administration procedures were used.

Biggs (1987b) SPQ has been designed for the university sector but is not subject specific. We have situated the questionnaire by adapting it for physics for three reasons. First, as students study courses in several disciplines in their first year it is important to clearly distinguish the discipline area that it is the focus of the inventory. This was done mostly by inserting the word physics into items. Second, the questionnaire was administered in the first few weeks of semester when many students are confused about university studies (White et al., 1995). Hence being specific about physics may reduce misinterpretation of the items. Lastly, the wording of some items was revised under consultation with an expert panel of physicists, so that wording best reflected the values of the discipline.

Data analysis: Three sets of analysis were carried out corresponding to each research question:

- Factor analysis and reliability analysis are used to determine the efficacy of the physics SPQ measure

- ANOVA is used to determine if there is a difference between the means for the three streams and three year cohorts, for each item and for the deep and surface scales

- Boxplots are used to compare groups by year and stream and illustrate any differences

\section{RESULTS}

Factor analysis and reliability: Factor analysis was done using Principal Components Analysis and Quartimax, an orthogonal rotation. Using the complete data set, each item was checked for normality and specificity and correlations were checked for multicollinearity. Factor loadings of less than .4 were excluded as per Field (2000). A satisfactory two-factor solution was produced, explaining $48 \%$ of the variance. On the whole the items least consistent with original SPQ factor solutions are not necessarily the ones that were modified. The reliability of the deep and surface scales of the physics adaption of the SPQ was calculated using Cronbach's alpha for the complete data set and separately for each stream. The internal consistency coefficient for the deep scale is $\alpha=0.86$ and for the surface scale $\alpha=0.64$. Reliabilites for the streams ranged from 0.61-0.90. $\mathrm{t}=$ the lowest, for the 


\section{J. Social Sci., 8 (2): 216-222, 2012}

surface scale in the Fundamentals stream is not high, but higher than those reported for the SPQ elsewhere; Biggs (1987a) $\alpha=0.51$ and Biggs et al. (2001) $\alpha=$ 0.57. The surface scale persistently records low reliabilities, for example Wilson and Fowler (2005) report a value of 0.55 for a surface subscale.

Comparison of the means of the streams: We compared the item and scale means using a one-way ANOVA. We also extracted non-standardised mean scores to better understand trends in student selfreporting of the scales and found that there is a significant difference amongst the three streams for items on the both SPQ-Physics surface and deep scales. These results meet significance levels as determined by the Bonferroni correction $(\mathrm{p}<0.05 \div 13=\mathrm{p} 0.004)$. For example, for item $\mathrm{A} 2$ on the deep scale there was a significant difference amongst the means $(\mathrm{F}=17$, $\mathrm{p}<0.004$, df $=2020)$ and similarly for A19 on the surface scale $(\mathrm{F}=29, \mathrm{p}<0.004, \mathrm{df}=2008)$. The Tukey post-hoc test showed that the mean difference between the Advanced and Fundamentals streams was much larger than the other mean differences for items on the deep scale, while for the surface scale the mean difference between the Regular and Fundamentals streams was much larger than the other mean differences.

Table 1 shows the means for the physics SPQ deep and surface scales for each stream. One way ANOVA showed that there was a significant difference amongst the three streams for the SPQPhysics deep factor score ( $\mathrm{F}=$ 24, $\mathrm{p}<0.05$, df =1942) and for the physics SPQ surface factor score $(\mathrm{F}=23, \mathrm{p}<0.05$, df $=1942)$. Not surprisingly, the Tukey test reflected the results of the comparison of the means of items for the different streams.

We found trends that are in keeping with expected behaviours for the deep scale. Students who have less experience with physics report, on average, less deep approaches to learning physics, while students who have more experience with physics report, on average, more deep approaches. The trends in students' self-reporting of surface approaches to learning physics are interesting. Students in the advanced stream, on average, report neutrally with regard to surface approaches; given their experience and achievement, we might have expected them to disagree with surface approaches. Students in the Regular stream report, on average, more surface approaches and the Fundamentals tend to show disagreement with surface approaches.

Impact of school syllabus change: To investigate if the scales are robust enough for the sum of the items to be used instead of factor scores, a comparison by stream and year was made, as shown in Table 1.
Table 1: Comparison of the mean score for each stream using the SPQP deep and surface scales. Standard errors of the means are given in parenthesis

\begin{tabular}{llll}
\hline & $\begin{array}{l}\text { Mean score } \\
\text { Advanced }\end{array}$ & Regular & Fundamentals \\
\hline SPQP deep scale & $+0.29(0.06)$ & $-0.05(0.03)$ & $-0.12(0.03)$ \\
SPQP surface scale & $-0.01(0.04)$ & $+0.14(0.03)$ & $-0.20(0.05)$ \\
\hline
\end{tabular}

These boxplots show the trends for the deep (a) and Surface (b) factor scores. We also examined the raw sums of deep and surface items and found similar trends.

Cohorts for 2002 and 2004 show similar trends, while 2001 is contrasting. This can be explained in terms of students' high school experiences. The 2001 cohort was exposed to a more traditional school physics syllabus while the later cohorts were exposed to a dramatically rejuvenated syllabus. The students exposed to the rejuvenated syllabus report more deep approaches to learning when compared with those exposed to the traditional syllabus, with the advanced stream demonstrating the largest increase. Furthermore, the students exposed to the rejuvenated syllabus also report more surface approaches to learning when compared with those exposed to the traditional syllabus, with the Fundamentals stream demonstrating the largest increase. We note that similar changes in syllabus were implemented across all sciences, implying that Fundamentals students could be influenced by perceptions and experiences in other disciplines. In view of the orthogonal nature of deep and surface approaches to learning, the increase in both scales is interesting and warrants further research.

We also examined gender across the deep and surface scales in the different streams. On the more reliable deep scale there were no significant gender differences, while on the surface scale, a significant difference was found using independent samples ttest for only the Advanced stream (mean factor score for females $=0.14$ and that for males -0.07 , $\mathrm{df}=412$, $\mathrm{t}=2.209, \mathrm{n}=414)$.

\section{DISCUSSION}

The use of the SPQ, with minor adaptations to specialise it for the physics context, has been supported by the factor analytic and reliability findings reported. There are clear trends in approaches to learning reported by students in the different first year streams. For example the advanced students report a neutral mean score for the surface scale while the Regular students agree with items on the surface scale. The Fundamentals students report negative mean scores for both scales and a more negative score for the surface score. So in essence the Fundamentals report few learning strategies while the Regulars report the wrong 
learning strategies (if deep learning is to occur). We cannot determine from this survey whether these findings are the result of school experience in physics alone (or lack of it in the case of Fundamentals students), student approaches to learning in others subjects, or indeed whether these trends have been impacted by the initial university experience. The question of how to facilitate a change towards deep approaches is the challenge for practising educators. As this study is part of a larger longitudinal investigation it will be interesting to follow students and their reported SPQ scores, as they progress in their degrees.

The differences between streams shows trends that are consistent with expected student behaviours. Even analysis at individual item level, using one-way ANOVA, shows differences and directions of differences as expected; with advanced students reporting the highest levels of deep approaches to learning. This study adds to the literature on trends in students' approaches to learning such as those by Zeegers (2001) and Gow et al. (1994) in investigating differences in approaches to learning across streams.

In view of our findings and those of Zeegers (2001), which raise concerns about if and how the Australian university students' experiences improve their approaches to learning; we propose that future discipline specific studies provide the opportunity to explore this in more detail. Encouragement can be taken from the fact that this suggests a strong relationship between the teaching and learning practices and contexts and student approaches to learning. There are many possibilities as to how teaching and learning practices might promote deeper approaches: by shifting teacher expectations; by influencing students' conceptions of their subject (Ellis et al., 2008; Georgiou and Sharma, 2010); by professional development of teachers (Kember et al., 2008; Sharma et $a l, 2010)$. Studies such as those by Gordon and Debus (2002) have demonstrated how deep approaches can be encouraged by implementing specific teaching and learning strategies.

Longitudinal findings are needed to inform debate on these concerns. For now our findings relating to physics study approaches at the outset of first year are more likely to reflect teaching and learning practices in high school. This is illustrated by the fact that those students educated under the old school syllabus (2000 and 2001 cohorts), show different trends to those who received the reformed physics syllabus (2004 cohort). A longitudinal analysis is planned so that these students progress through their degrees can be examined. Hayes et al. (2010), Sanders and Healeys' longitudinal study (2010) of physical therapy students tracks their approaches to learning and GPA attainment throughout the span of their degrees. They found that those who retained their deep and surface approaches, measured at outset, were likely to lose academic self-confidence and use fewer strategic approaches to study. Those students who increased their deep approaches to learning, by contrast, were able to retain high academic self-concept and maintain strategic study habits. Some of Heyes' and colleagues' findings were consistent with the teaching and learning contexts of the degree; they noted that clinical emphases and interactive teaching in second year was associated with an overall increase in deep approaches.

A study similar to Hayes et al. (2010) examining physics learning is needed to establish the dynamics between teaching, curriculum and approaches to learning across the span of a typical physics degree. In particular we are interested to examine the impact of assessment upon students' approaches to learning; this has not been examined in physics, or elsewhere. Recent promotion and increased practice of formative assessment approaches holds potential to direct students toward deeper approaches to learning. Authentic assessment practices focus on higher order and metacognitive skills that are central to deep learning.

Where the Fundamentals students currently report low levels of both deep and surface study strategies, there is potential to nurture learning in the future. As the fundamentals students present as 'tabula rasa' the faculty has a unique opportunity to introduce deep approaches by careful design of their experiences in first year physics. We need also to foster deep approaches in the Regular stream and to support such approaches in the advanced stream. We can support deep approaches, according to the $3 \mathrm{P}$ model, by investigating individual SPQ items and relating these to curriculum and course design.

\section{CONCLUSION}

This study has used a minimally adapted SPQ to survey student approaches to learning in first year physics. Differences between Advanced, Regular and fundamentals streams are consistent with expectations, given that deep approaches to learning are seen to correlate with higher attainment. Differences were also identified between cohorts exposed to contrasting high school physics curricula. Both these findings reflect the contextualised nature of approaches to study, with students differing approaches related to their differing exposure to physics. The findings are particularly valuable to faculty staff and will inform teaching and learning practice. For the wider community the findings are yet another illustration of the powerful and complex ways in which students are moulded by educational experience. 


\section{J. Social Sci., 8 (2): 216-222, 2012}

\section{ACKNOWLEDGEMENT}

The reaches acknowledge Science Faculty Education Research (SciFER) grants, University of Sydney and support from staff and students. The authors are grateful to Professor David Boud for his constructive feedback on this study.

\section{REFERENCES}

Alexander, P.A., P.K. Murphy, B.S. Woods, K.E. Duhon and D. Parker, 1997. College instruction and concomitant changes in students' knowledge, interest and strategy use: A study of domain learning. Contemporary Educ. Psychol., 22: 125146. DOI: $10.1006 /$ ceps.1997.0927

Biggs, J.B., 1987a. Student Approaches to Learning and Studying. 1st Edn., Australian Council for Educational Research, Melbourne, ISBN-10: 0855634162 pp: 145.

Biggs, J.,1987b. Study process questionnaire manual. Student approaches to learning and studying. 1st Edn., Australian Council for Educational Research, Melbourne, ISBN-10: 0855634162 pp:44.

Biggs, J., 1993. What do inventories of students' learning processes really measure? A theoretical review and clarification. Brit. J. Educ. Psychol., 63: 3-19. DOI: 10.1111/j.2044-8279.1993.tb01038.x

Biggs, J., D. Kember and D.Y.P. Leung, 2001. The revised two-factor Study Process Questionnaire: RSPQ-2F, British J. Educ. Psychol., 71: 133-149. DOI: 10.1348/000709901158433

Binnie, A., 2004. Development of a senior physics syllabus in New South Wales. Physics Educ., 39: 490-495. DOI:10.1088/0031-9120/39/6/004

Burnett, P.C. and B.C. Dart, 2000. The study process questionnaire: A construct validation study. Assess. Evaluat. Higher Educ., 25: 903-100. DOI: 10.1080/713611415

Christensen, C.A., D.R. Massey and P.J. Isaacs, 1991. Cognitive strategies and study habits: An analysis of the measurement of tertiary students' learning. British J. Educ. Psychol., 61: 290-299. DOI: 10.1111/j.2044-8279.1991.tb00986.x

Craik, F.I.M. and R.S. Lockhart, 1972. Levels of processing: A framework for memory research. J. Verbal Learn. Verbal Behav., 11: 671-684. DOI: 10.1016/S0022-5371(72)80001-X

Craik, F.I.M., 1979. Human memory. Ann. Rev. Psychol., 30: 63-102.

Crawford, K., S. Gordon, J. Nicholas and M. Prosser, 1998a. University mathematics students' conceptions of mathematics. Stud. Higher Educ., 23: 87-94. DOI: 10.1080/03075079812331380512
Crawford, K., S. Gordon, J. Nicholas and M. Prosser, 1998b. Qualitatively different experiences of learning mathematics at university. Learn. Instr., 8: 455-468. DOI: 10.1016/S0959-4752(98)00005-X

Ellis, R.A., P. Goodyear, M. Brillant and M. Prosser, 2008. Student experiences of problem-based learning in pharmacy: Conceptions of learning, approaches to learning and the integration of faceto-face and on-line activities. Adv. Health Sci. Educ.: Theory Practice, 13: 675-692. DOI: 10.1007/s10459-007-9073-3

Entwistle, N. and V. McCune, 2004. The conceptual bases of study strategy inventories. Educ. Psychol. Rev., 16: 325-345. DOI: 10.1007/s10648-0040003-0

Field, A.P., 2000. Discovering Statistics Using SPSS for Windows Advanced Techniques for the Beginner. 1st Edn., Sage Publications, London, ISBN-10: 0761944524, pp: 496.

Fox, R.A., I.C. McManus and B.C. Winder, 2001. The shortened study process questionnaire: An investigation of its structure and longitudinal stability using confirmatory factor analysis. Brit. J. Educ. Psychol., 71: 511-530. DOI: 10.1348/000709901158659

Georgiou, H. and M.D. Sharma, 2010. A report on a preliminary diagnostic for identifying thermal physics conceptions of tertiary students. Int. J. Innovat. Sci. Math. Educ., 18: 32-51.

Gordon, C. and R. Debus, 2002. Developing deep learning approaches and personal teaching efficacy within a preservice teacher education context. British J. Educ. Psychol., 72: 483-511. DOI: 10.1348/00070990260377488

Gow, L., D. Kember and B. Cooper, 1994. The teaching context and approaches to study of accountancy students. Issues Account. Educ., 9: 118-126.

Hayes, K., B. Sanders and W. Healey, 2010. Students' study approaches in a new curriculum. J. Physical Therapy Educ., 24: 3-27.

Jacobs, P.A. and S.E. Newstead, 2000. The nature and development of student motivation. Brit. J. Educ. Psychol., 70: 243-254. DOI: 10.1348/000709900158119

Kember, D., A. Wong and D.Y.P. Leung, 1999. Reconsidering the dimensions of approaches to learning. Brit. J. Educ. Psychol., 69: 323-343. DOI: 10.1348/000709999157752

Kember, D., D.Y.P Leung and C. McNaught, 2008. A workshop activity to demonstrate that approaches to learning are influenced by the teaching and learning environment. Active Learn. Higher Educ., 9: 43-56. DOI: $10.1177 / 1469787407086745$ 
Laird, T.F.N., R. Shoup, G.D. Kuh and M.J. Schwarz, 2008. The effects of discipline on deep approaches to student learning and college outcomes. Res. Higher Educ., 49: 469-494. DOI: 10.1007/s11162008-9088-5

Laird, T.F.N. and A.K. Garver, 2010. The effect of teaching general education courses on deep approaches to learning: How disciplinary context matters. Res. Higher Educ., 51: 248-265. DOI: 10.1007/s11162-009-9154-7

Langan, D. and J. Athanasou, 2005. Testing a model of domain learning in music therapy. J. Music Therapy, 42: 296-313. PMID: 16411788

Quinnell, R., E. May, M. Peat and C. Taylor, 2005. Creating a reliable instrument to assess students' conceptions of studying biology at tertiary level. School Biol. Sci., pp: 87-92.

Sharma, M.D., I.D. Johnston, H.M. Johnston, K.E. Varvell and J.G. Robertson et al., 2010. Use of interactive lecture demonstrations: A ten year study. Phys. Rev. Special Topics-Phys. Educ. Res., 6: 1-9.

Skogsberg, K. and M. Clump, 2003. Do psychology and biology majors differ in their study processes and learning styles. College Student J., 37: 27-34.
White, R., R. Gunstone, E. Elterman, I. MacDonald and B. McKittrick et al., 1995. Students' perceptions of teaching and learning in first-year university physics. Res. Sci. Educ., 25: 465-478. DOI: 10.1007/BF02357388

Wilson, K.L., R.M. Smart and R.J. Watson, 1996. Gender differences in approaches to learning in first year psychology students. British J. Edu. Psychol., 66: 59-71. DOI: 10.1111/j.20448279.1996.tb01176.x

Wilson, K. and J. Fowler, 2005. Assessing the impact of learning environments on students' approaches to learning: Comparing conventional and action learning designs. Assess. Evalu. Higher Edu., 30: 87-101. DOI: $10.1080 / 0260293042003251770$

Wilson, R., M. Sharma and S. Georgakis, 2011. The relationships between school curriculum and university students' conceptions of their subject. Proceedings of the International Conference on Education, (ICE' 11), Samos, Greece, pp: 5-9.

Zeegers, P., 2001. Approaches to learning in science: A longitudinal study. Brit. J. Educ. Psychol., 22: 115132. DOI: $10.1348 / 000709901158424$ 